\title{
Evaluation of Mast Cell Density in the Tumor Microenvironment in Oral Epithelial Dysplasia and Oral Squamous Cell Carcinoma
}

\author{
Rebeca C.M. Dantas, MSc, * Renata O. de Souza, MSc, $†$ Ludmila de F. Valverde, MSc, $\dagger$ \\ Manuela T.A. Vidal, MSc, † Caroline B.S. Sales, PhD, $\neq$ Letícia P. Sousa, BSc $\dagger$ \\ Jean N. dos Santos, PhD, $\S$ Eduardo A.G. Ramos, PhD, $\dagger$ and Clarissa A. Gurgel Rocha, PhD $†$
}

\begin{abstract}
The objective of this study was to compare mast cell density (MCD) in oral epithelial dysplasias (OED) and oral squamous cell carcinoma (OSCC) and determine its correlation with clinical and histopathologic parameters and the degree of tumor differentiation. Thirty OSCC samples, 14 OED samples, and 4 non-neoplastic oral mucosa samples were analyzed by immunohistochemistry to determine MCD based on the expression of MC tryptase. In addition, MCs were categorized morphologically into degranulated and granulated cells. MCD was significantly higher in OSCC lesions with a greater degree of differentiation $(P=0.04)$. No significant difference in MCD was detected between mild and moderate OED samples $(P=0.09)$. Our findings indicate that MCs are present in the tumor microenvironment and may be associated with a better prognosis.
\end{abstract}

Key Words: mast cell, oral squamous cell carcinoma, oral epithelial dysplasia, mast cell density, mast cell tryptase

(Appl Immunohistochem Mol Morphol 2017;25:e83-e88)

$\mathrm{O}$ ral squamous cell carcinoma (OSCC) is a public health problem and the most common neoplasia of the oral cavity, representing $\sim 95 \%$ of all malignant tumors that affect this anatomic site. ${ }^{1,2}$ OSCC is associated with high-morbidity and mortality rates and a $25 \%$ to $50 \%$ chance of developing metastasis. ${ }^{3}$ Particularly in Brazil, oral cancer is one of the most frequent tumor types. For the year 2016, 15,490 new cases of oral cancer were estimated, 11,140 for males and 4350 for females. ${ }^{4}$ Despite

Received for publication February 20, 2017; accepted July 31, 2017.

From the *School of Dentistry of the Federal University of Bahia; † Laboratory of Pathology and Molecular Biology, Oswaldo Cruz Foundation; IInstitute of Health Science, Federal University of Bahia; and §Laboratory of Oral Surgical Pathology, School of Dentistry of the Federal University of Bahia, Bahia, Brazil.

Supported by National Council for Scientific and Technological Development (CNPq, Brazil), grant number: 4768572011-2.

The authors declare no conflict of interest.

Reprints: Clarissa A. Gurgel Rocha, PhD, Oswaldo Cruz Foundation, Rua Waldemar Falcão, 121, Candeal, Salvador, Bahia 40296-710, Brazil (e-mail: clarissa.gurgel@bahia.fiocruz.br).

Copyright (C) 2017 Wolters Kluwer Health, Inc. All rights reserved. advances in treatment, the 5-year survival rate remains $<50 \%$ in patients with advanced stages of the disease. . $^{1,3,5,6}$

As OSCC is frequently preceded by premalignant oral lesions, it is believed to originate from histologic stages of dysplastic changes. ${ }^{7,8}$ In fact, it has been reported that premalignant lesions with dysplasia are more likely to evolve to carcinoma, but the underlying mechanisms of this change remain unknown. ${ }^{8}$ To date, there is no reliable method to predict whether a premalignant oral lesion will develop into a neoplasia or not. ${ }^{7}$ Thus, several studies have investigated molecular markers that could be used to support the diagnosis and prognosis of oral epithelial dysplasias (OEDs) and OSCC. ${ }^{9,10}$

Mast cells (MCs) are known to release preformed mediators of inflammation, immune reactions, allergy, and tissue damage repair..$^{11-14}$ Several studies have associated the presence of MCs with the development of human tumors, including oral cancer, thyroid carcinoma, prostate carcinoma, lung adenocarcinoma, and melanoma. $1,15-18$

MCs accumulate in the tumor microenvironment near the blood vessels and are involved in antitumor and protumor functions, which may affect tumor growth and progression and its ability to metastasize. ${ }^{17,18}$ It is believed that these antagonistic features of MCs in tumor progression occur due to the selective release of mediators and depend on specific conditions. In addition, MCs can be exposed to signals that may be favorable or unfavorable to tumor growth and development. ${ }^{18-20}$

In vivo studies have shown that MC infiltration and degranulation occur during oral carcinogenesis and that the activation of these cells highly correlateswith the distinct phases of dysplasia, carcinoma in situ, and invasive carcinoma. ${ }^{21}$ However, the antitumor or protumor role of MCs in OEDs and OSCCs is still not well established. Thus, the objective of this study was to evaluate the density of MCs in OED and OSCC lesions and its correlation with different histologic grades of the lesions.

\section{MATERIALS AND METHODS}

After institutional review board approval by the Human Research Ethics Committee at the Gonçalo Moniz Research Center (FIOCRUZ, Bahia), 14 OED and 30 OSCC samples from AC Camargo Hospital (São Paulo, Brazil) and Aristides 
Maltez Hospital (Salvador, Bahia, Brazil), respectively, were examined. The exclusion criteria were lack of preserved tissue, fewer than 3 areas suitable for analysis (hot spots), and lip lesions. Data on sex, age, and location of OED and OSCC lesions from the patients included in the sample were collected. In addition, we compared the expression of MC tryptase in OED and OSCC lesions with that of histologically normal tissues from 4 non-neoplastic oral mucosa (NNM) samples obtained from healthy, nonsmoking, and nonalcoholic patients following removal of impacted third molars.

OED and OSCC specimens were stained with hematoxylin-eosin and classified according to World Health Organization criteria (2005) in mild, moderate, and severe dysplasia or well-differentiated, moderately differentiated, and poorly differentiated OSCC.

\section{Immunohistochemistry Study}

Formalin-fixed, paraffin-embedded specimens were cut into 4- $\mu$ m-thick sections. Histologic sections were dewaxed in xylol and rehydrated with alcohol. For exposure of the antigenic epitopes, antigen retrieval of sections was performed with trypsin $1 \%(\mathrm{w} / \mathrm{v})$ in an oven at $37^{\circ} \mathrm{C}$ for 30 minutes. Endogenous peroxidase blockade (Peroxidase Blocking Solution; Dako, Carpinteria, CA) was performed with light protection for 10 minutes.

For MC detection, sections were incubated with anti-MC tryptase primary antibody (clone AA1; Novocastra Laboratories, Newcastle, UK) at 1:50 dilution for 1 hour, followed by incubation with the EnVisionreagent (Dako) for 30 minutes, both at room temperature. Sections were developed with 3,3-diaminobenzidine (Dako) in a darkroom and the slides were counterstained with Harris' hematoxylin and mounted with natural Canada balsam. Mastocytosis samples (specimens/cases) were used as positive controls and the primary antibody replaced by normal serum of the same isotype was used as negative control.

\section{Immunohistochemistry Analysis}

For analysis, positive immunostaining detection of MCs and the presence or absence of MC degranulation were evaluated in NNM, OED, and OSCC samples. The analysis was performed by an experienced pathologist (E.A.G.R.) who selected 3 to 5 areas with greater immunostaining (hot spots) in each slide using an Axiostar Plus light microscope (ZEISS, Germany) at $\times 200$ magnification. The images of the selected areas were captured using an AXIOCAM ICc3 digital microscope camera (ZEISS) and visualized using the Image $\mathrm{J} 1.44$ software (National Institutes of Health, Bethesda, MD). The images were measured in $\mathrm{mm}^{2}$ using Image-Pro Plus version 5 software (Media Cybernetics Inc., Rockville, MD) after calibration. Then, MC density (MCD) was calculated from the number of MCs per $\mathrm{mm}^{2}\left(\right.$ cells $\left./ \mathrm{mm}^{2}\right)$.

For the qualitative evaluation of MC morphology, the same areas described above were visualized using Image J 1.44 software (National Institutes of Health). MCs were considered degranulated, when tryptase-positive granules were extracytoplasmic, or granular, with brownish staining inside the cell.

\section{Statistical Analysis}

Data analysis was performed using GraphPad Prism version 5.0 (GraphPad Software Inc., San Diego, CA).

The Mann-Whitney test was used to compare 2 independent samples and the Kruskal-Wallis test and the Dunn post hoc test were used to compare $>2$ independent samples. A $P$-value $<0.05$ was considered statistically significant.

\section{RESULTS}

The clinical and histologic characteristics of OED and OSCC lesions are described in Table 1. The mean age of patients with OED and OSCC was $65.29 \pm 14.55$ years (range: 43 to $91 \mathrm{y}$ ) and $58.73 \pm 10.63$ years (range: 36 to 81 y), respectively.

\section{MCD and Expression}

MCs had brownish color, oval, elongated, and/or round shape, and were often localized near blood vessels.

In NNM samples, MCD ranged from 47.3 to 75.0 cells $/ \mathrm{mm}^{2}$ (median: $67.85 \mathrm{cells} / \mathrm{mm}^{2}$ ). A predominance of MC granulates was observed in all samples.

All OED samples showed MC staining. Among the 14 samples, $10(71.42 \%)$ predominantly had granulated MCs and $4(28.57 \%)$ had degranulated MCs. Most lesions in samples with granulated $(5 / 10,50 \%)$ and degranulated cells $(3 / 4,75 \%)$ were classified as mild. MCD ranged from 31.25 to $143.57 \mathrm{cells} / \mathrm{mm}^{2}$ in OED samples (median: 92.58 cells $/ \mathrm{mm}^{2}$ ). Median MCD was 83.57, 103.6, and 143.57 cells $/ \mathrm{mm}^{2}$ in mild, moderate, and severe OED samples, respectively. It was not possible to compare mild and moderate OED samples with severe OED because the

TABLE 1. Clinical and Histologic Characteristics of Patients With Oral Epithelial Dysplasia (OED) and Oral Squamous Cell Carcinoma (OSCC)

\begin{tabular}{|c|c|c|c|}
\hline \multicolumn{2}{|c|}{ OED } & \multicolumn{2}{|c|}{ OSCC } \\
\hline $\begin{array}{l}\text { Clinical } \\
\text { Parameters }\end{array}$ & $\begin{array}{c}\text { Total } \\
\text { [n (\%)] }\end{array}$ & $\begin{array}{c}\text { Clinical } \\
\text { Parameters }\end{array}$ & $\begin{array}{l}\text { Total } \\
{[n(\%)]}\end{array}$ \\
\hline \multicolumn{4}{|l|}{ Sex } \\
\hline Male & $9(64.28)$ & Male & $20(66.66)$ \\
\hline Female & $5(35.71)$ & Female & $10(33.33)$ \\
\hline \multicolumn{4}{|l|}{ Anatomic location } \\
\hline Tongue & $5(35.71)$ & Floor of mouth & $10(33.33)$ \\
\hline Jugal mucosa & $3(21.43)$ & Tongue & $7(23.33)$ \\
\hline Floor of mouth & $3(21.43)$ & Palate & $4(13.33)$ \\
\hline Palate & $1(7.14)$ & $\begin{array}{l}\text { Floor of mouth } \\
\text { and tongue }\end{array}$ & $3(10.0)$ \\
\hline Gingival ridge & $1(7.14)$ & Gingiva & $2(6.66)$ \\
\hline \multirow[t]{3}{*}{ No information } & $1(7.14)$ & Retromolar area & $1(3.33)$ \\
\hline & & Jugal mucosa & $1(3.33)$ \\
\hline & & No information & $2(6.66)$ \\
\hline \multicolumn{4}{|l|}{ Histologic grading } \\
\hline Mild & $8(57.14)$ & Well differentiated & $13(43.33)$ \\
\hline Moderate & $5(35.71)$ & $\begin{array}{l}\text { Moderately } \\
\text { differentiated }\end{array}$ & $10(33.33)$ \\
\hline Severe & $1(7.14)$ & Poorly differentiated & $7(23.33)$ \\
\hline
\end{tabular}


OED
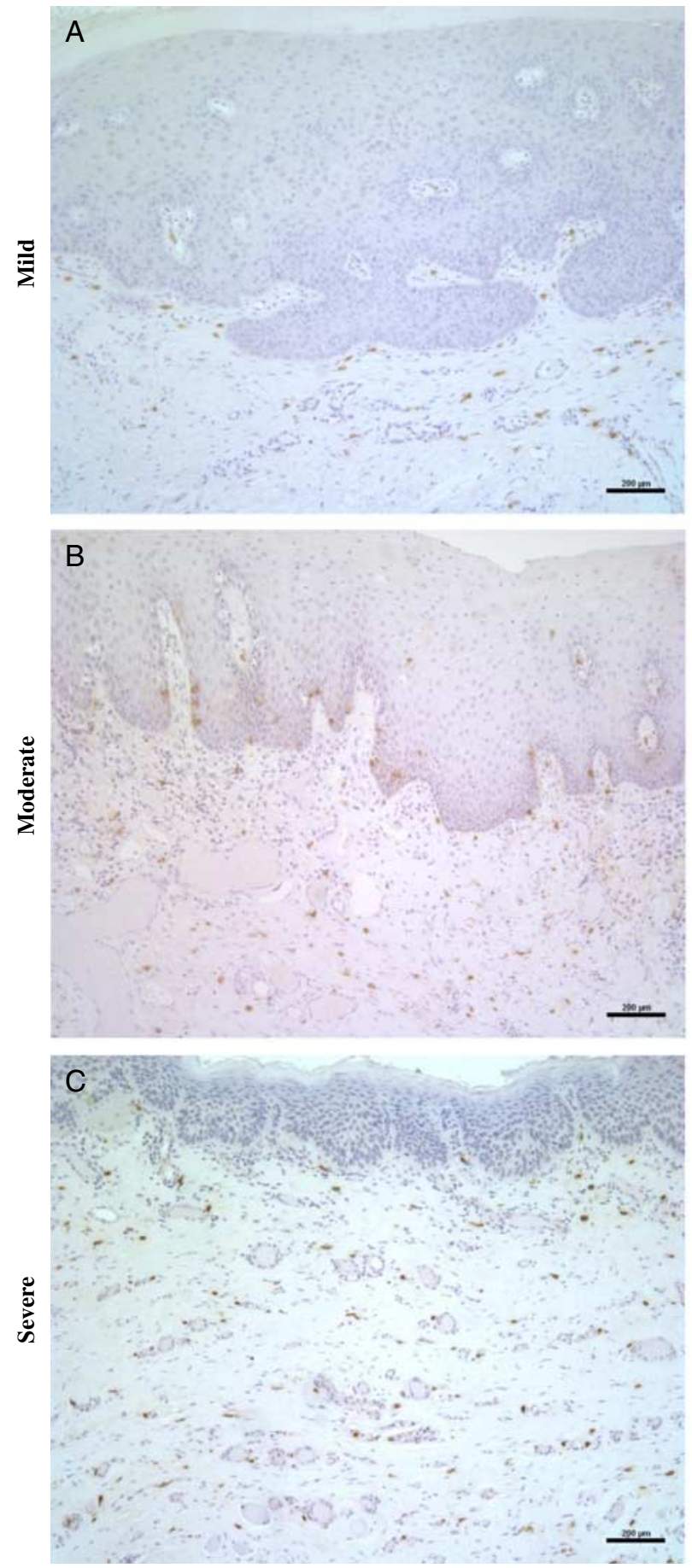
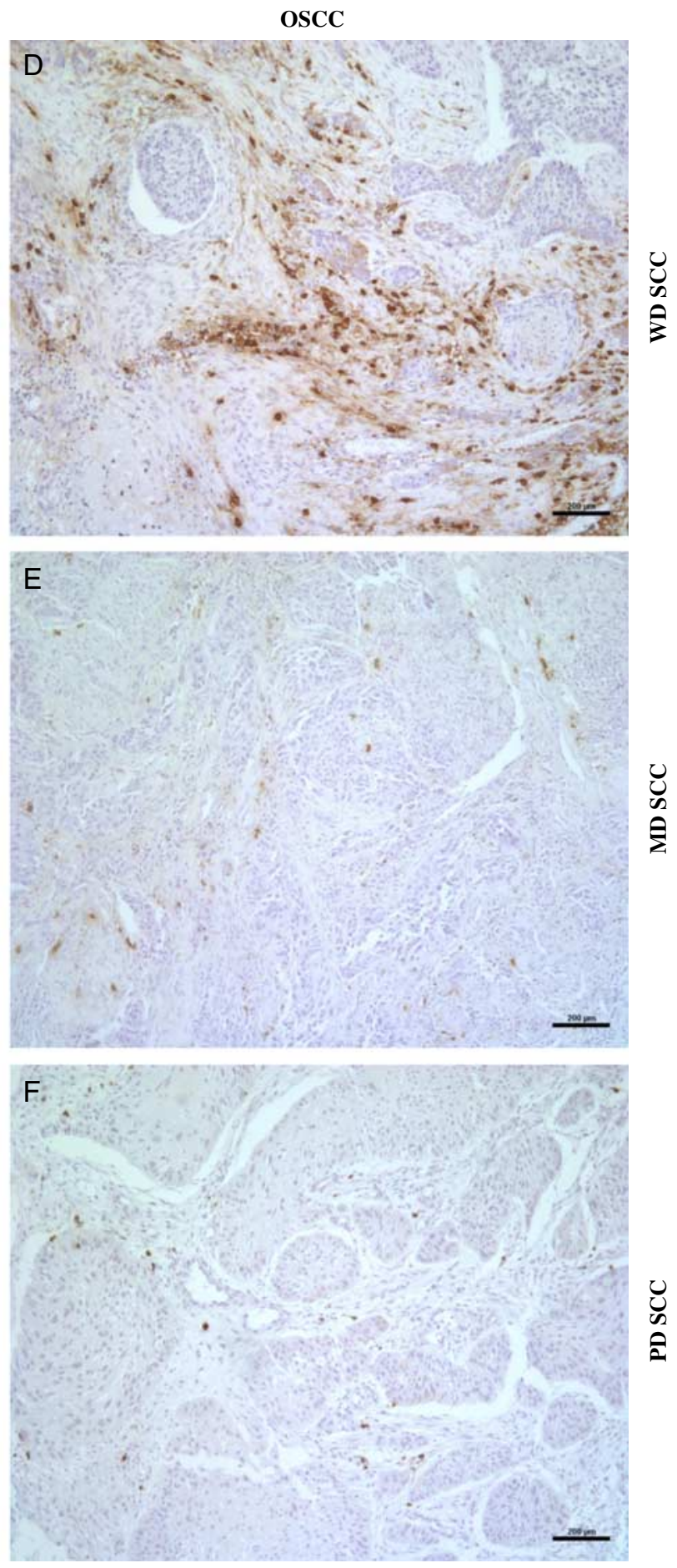

FIGURE 1. Mast cell tryptase in OED and OSCC samples. A-C, Mild, moderate, and severe OED, respectively. D-F, Well-differentiated (WD), moderate-differentiated (MD), and poorly differentiated (PD) OSCC, respectively. OED indicates oral epithelial dysplasias; OSCC, oral squamous cell carcinoma.

latter group had only 1 sample. Overall, no significant difference was detected between mild and moderate OED samples (Mann-Whitney test, $P=0.09$; Figs. 1, 2).

Among the 30 OSCC samples, $29(96.66 \%)$ had positive staining for MCs. Among the 30 samples, 16
(55.17\%) predominantly had granulated MCs and 13 $(44.82 \%)$ had degranulated MCs. The same number of lesions with well $(5 / 10,31.25 \%)$ and moderately differentiated OSCCs $(5 / 10)$ was observed in samples with granulated cells, whereas most lesions in samples with 


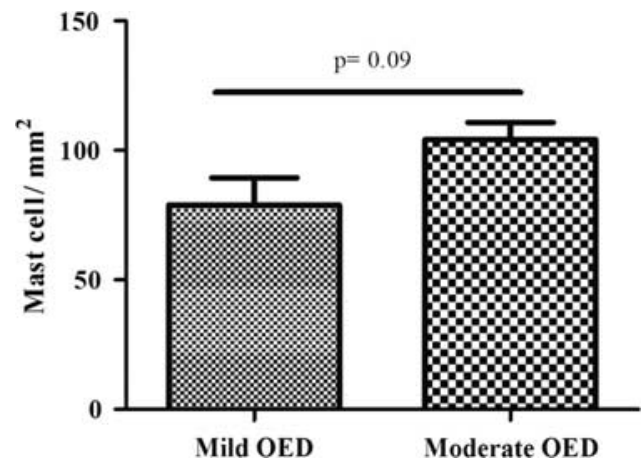

FIGURE 2. Distribution of mast cell in mild and moderate OED. OED indicates oral epithelial dysplasias.

degranulated cells were well-differentiated OSCCs $(8 / 13$, $61.53 \%$ ). Overall, median MCD in OSCC samples was 61.07 cells $/ \mathrm{mm}^{2}$ and $148.2,75.36$, and $42.85 \mathrm{cells} / \mathrm{mm}^{2}$ in well-differentiated, moderately differentiated, and poorly differentiated OSCCs, respectively. MCD was significantly higher in OSCCs with a greater degree of differentiationwell and moderately differentiated OSCCs (Kruskal-Wallis test, $P=0.04$, Figs. 1, 3) - than poorly differentiated OSCCs (The Dunn post hoc test, $P<0.005$ ).

\section{DISCUSSION}

Cancers of the oral cavity can be preceded by premalignant lesions, referred to as OEDs, which have a risk of malignant progression of $\sim 9 \%$ to $11 \%{ }^{11,22,23}$ Thus, it is important to characterize biological markers and tissue components that may predict malignant transformation. ${ }^{24}$ In this study, MCD was evaluated in OED, OSCC, and histologically normal oral mucosa (NNM) tissues. We also investigated the relationship of MCD with clinical-pathologic findings and the degree of tumor differentiation. In addition, MCs were categorized morphologically into degranulated and granulated cells.

Many studies have linked the presence of MCs to tumor development because these cells synthesize and release a heterogenous group of molecules capable of promoting or

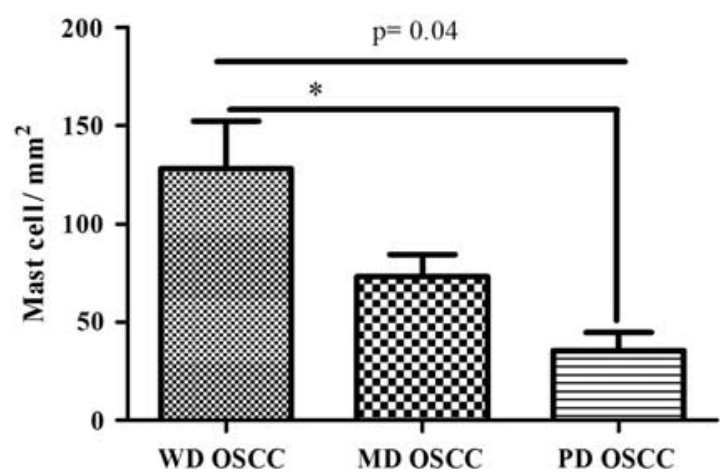

FIGURE 3. Distribution of mast cell in well-differentiated (WD), moderate-differentiated (MD) and poorly differentiated (PD) OSCC. OSCC indicates oral squamous cell carcinoma. *MCD was significantly higher in well and moderately differentiated OSCCs than poorly differentiated OSCCs $(p=0.04)$. facilitating tumor growth. ${ }^{25}$ MCs may support tumor progression because they are activated to secrete various mediators that induce angiogenesis, proliferation of neoplastic cells, degradation and remodeling of extracellular matrix components, and immunosuppression. ${ }^{26}$ Thus, in addition to storing chemical mediators of inflammation and several proangiogenic factors, MCs also synthesize tryptases and chymases, which act in the extracellular matrix promoting the degradation of its components and tissue remodeling, providing space for the dissemination of tumor cells and, consequently, contributing to neoplastic progression and metastasis. ${ }^{27}$

In our study, MCs were stained by immunohistochemistry using the anti-MC tryptase antibody. The density of MCs in tissues can be examined histochemically using stains such as toluidine blue and alcian blue and immunohistochemically using antibodies against MC tryptase, heparin, chymase, and carboxypeptidase A. ${ }^{2,13}$ However, immunohistochemistry is more specific and sensitive, and tryptase is a specific marker of MCs, which stains only the granules of MCs. ${ }^{28}$

NNM samples were used as controls to the oral lesions. In our study, NNM had high MCD $\left(67.85 \mathrm{cells} / \mathrm{mm}^{2}\right)$ and a predominance of granulated MCs was observed in all cases. Kathuriya et $\mathrm{al}^{29},{ }^{29}$ Zaidi and Mallick, ${ }^{30}$ and Pyziak et $\mathrm{al}^{17}$ found low MCD in NNM samples: 32.85, 22.75, and 27.3 cells $/ \mathrm{mm}^{2}$, respectively. In addition, Zaidi and Mallick ${ }^{30}$ found $61 \%$ of granulated MCs in NNM samples. According to Kinra et $\mathrm{al}^{31}$ the number and distribution of MCs in histologically normal oral tissues is controversial, because inflammation is a frequent event in the oral mucosa that can affect the identification of MCs. ${ }^{32}$

A progressive increase in MCD was observed with the increasing degree of dysplasia, but there was no significant difference in MCD between mild, moderate, and severe lesions. Similar results were reported by Michailidou et al, ${ }^{11}$ who observed that MCD in cases of leukoplakia with mild and moderate dysplasia was lower than those in cases of leukoplakia with severe dysplasia. In the study by Sathyakumar et $\mathrm{al}^{33} \mathrm{MCD}$ increased significantly from normal oral mucosa to low-degree dysplasia and high-degree dysplasia. Conversely, Michailidou et $\mathrm{al}^{34}$ found higher MCD in discrete dysplasia. Comparisons with other studies were complicated by methodological differences, because most studies do not categorize lesions according to histologic gradation. Thus, it is necessary to standardize the description of oral lesions to enable accurate comparisons of results from the available literature and provide a more conclusive understanding of the role of MCs in OED and OSCC lesions.

In the current study, MCD was significantly higher in OSCC lesions with a greater degree of differentiation $(P=0.043)$, especially well and moderately differentiated lesions (The Dunn post hoc test, $P<0.005$ ). Similar findings were reported by Kalra et $\mathrm{al}^{6}$ and Cheema et $\mathrm{al}^{1}{ }^{1}$ who also found a larger number of MCs in more differentiated tumors and an inverse correlation between MCD and the degree of lesion differentiation. Conversely, Kathuriya et $\mathrm{al}^{29}$ found a significantly higher MCD in well-differentiated OSCC lesions compared with normal oral mucosa, but lower than 
that of moderately differentiated lesions. Jandinski et $\mathrm{al}^{35}$ also found a higher MCD in well-differentiated carcinomas and suggested an immunologic cause for this result. The lower MCD in moderately and poorly differentiated carcinomas has been attributed to an unfavorable cellular environment, suggesting that the reduction in MCD might be caused by competition between the cellular immune system and the tumor microenvironment.

In our study, we evaluated the presence of granulated and degranulated cells in OED and OSCC lesions to determine if MCs showed signs of activation by releasing mediators in tissues around the lesions. The results suggest that the different morphologic types of MCs do not have different activities in OED and OSCC. However, further studies with larger sample sizes should be performed to elucidate these findings.

MCD was higher in OED $\left(92.56\right.$ cells $\left./ \mathrm{mm}^{2}\right)$ than in OSCC $\left(61.07\right.$ cells $\left./ \mathrm{mm}^{2}\right)$ and NNM $\left(67.85\right.$ cells $\left./ \mathrm{mm}^{2}\right)$ samples, but the difference was not significant. A similar result was reported by Oliveira-Neto,${ }^{36}$ who found that the number of MCs in premalignant lesions was higher than in OSCC lesions. The author attributed this difference to MC migration failure due to decreased expression of chemotactic molecules such as stem cell factors and, possibly, to a significant change in the tumor microenvironment. Alternatively, these findings may have been a result of the complex signaling network in the tumor microenvironment, which may regulate the number of MCs in these neoplasms by inducing apoptosis and the antitumor functions of MCs, including natural cytotoxicity and secretion of molecules that promote tumor regression. ${ }^{37}$

The methods for analysis of MCD differ considerably across studies and some of these techniques are not consistent between studies preventing the use of the same protocol in future studies. Thus, studies using different methods and with a larger number of cases, especially cohorts of patients with OED, are necessary to establish the correlation between MCD and tumor progression.

In conclusion, the lower MC density in OSCC than in OED lesions reflects an important alteration in the tumor microenvironment that may trigger the invasion and proliferation of neoplastic cells. Finally, the higher MCD in well-differentiated OSCC tumors may indicate the participation of MCs in the regulation of tumor behavior and be associated with a better prognosis.

\section{REFERENCES}

1. Cheema VS, Ramesh V, Balamurali PD. The relevance of mast cells in oral squamous cell carcinoma. J Clin Diagn Res. 2012;6:1803-1807.

2. Chandolia B, Basu SK, Kumar M. Can MMP-9 be a prognosticator marker for oral squamous cell carcinoma? J Clin Diagn Res. 2016;10: ZC09-ZC13.

3. Alaeddini M, Abachi H, Abbasi S, et al. Association of stromal factors with the histologic risk assessment model in oral squamous cell carcinoma. Appl Immunohistochem Mol Morphol. 2017;25:129-133.

4. Brazil, Ministry of Health. Estimate 2016 - Cancer Incidence in Brazi. 2015. Avaliable at: http://www.inca.gov.br/estimativa/2016/ estimativa-2016-v11.pdf. Accessed July 18, 2017.

5. Malik UU, Zarina S, Pennington SR. Oral squamous cell carcinoma: key clinical questions, biomarker discovery, and the role of proteomics. Arch Oral Biol. 2016;63:53-65.
6. Kalra M, Rao N, Nanda K, et al. The role of mast cells on angiogenesis in oral squamous cell carcinoma. Med Oral Patol Oral Cir Bucal. 2012;17:e190-e196.

7. AbdulMajeed AA, Farah CM. Can immunohistochemistry serve as an alternative to subjective histopathological diagnosis of oral epithelial dysplasia? Biomark Cancer. 2013;5:49-60.

8. Izumo T. Oral premalignant lesions: from the pathological viewpoint. Int J Clin Oncol. 2011;16:15-26.

9. Sharma B, Sriram G, Saraswathi T, et al. Immunohistochemical evaluation of mast cells and angiogenesis in oral squamous cell carcinoma. Indian J Dent Res. 2010;21:260-265.

10. Reibel J. Prognosis of oral pre-malignant lesions: significance of clinical, histopathological, and molecular biological characteristics. Crit Rev Oral Biol Med. 2003;14:47-62.

11. Michailidou EZ, Markopoulos AK, Antoniades DZ. VEGF expression from human dysplastic or malignant oral epithelium may be related to mast cell density and the subsequent angiogenetic phenomena. Int J Oral Maxillofac Surg. 2012;41:1467-1473.

12. Tahir A, Nagi AH, Ullah E, et al. The role of mast cells and angiogenesis in well-differentiated oral squamous cell carcinoma. J Cancer Res Ther. 2013;9:387-391.

13. Telagi N, Ahmed Mujib BR, Kulkarni PG, et al. The master switch: comparative study of mast cell in oral epithelial dysplasia, oral submucous fibrosis and oral squamous cells carcinoma and their association with inflammation and angiogenesis. J Oral Maxillofac Pathol. 2015;19:25-29.

14. Visciano C, Prevete N, Liotti F, et al. Tumor-associated mast cells in thyroid cancer. Int $J$ Endocrinol. 2015;2015:705169.

15. Takanami I, Takeuchi K, Naruke M. Mast cell density is associated with angiogenesis and poor prognosis in pulmonary adenocarcinoma. Cancer. 2000;88:2686-2692.

16. Grimbaldeston MA, Pearce AL, Robertson BO, et al. Association between melanoma and dermal mast cell prevalence in sununexposed skin. Br J Dermatol. 2004;150:895-903.

17. Pyziak, L, Stasikowska-Kanicka, O, Danilewicz M, et al. Immunohistochemicalanalysisof mast cell infiltrates and microvessel density in oral squamouscell carcinoma. Pol J Pathol. 2013;64:276-280.

18. de Souza Junior DA, Santana AC, da Silva EZ, et al. The role of mast cell specific chymases and tryptases in tumor angiogenesis. Biomed Res Int. 2015;2015:1-13.

19. Khazaie K, Blatner NR, Khan MW, et al. The significant role of mast cells in cancer. Cancer Metastasis Rev. 2011;30:45-60.

20. Kormelink TG, Abudukelimu A, Redegeld FA. Mast cells as target in cancer therapy. Curr Pharm Des. 2009;15:1868-1878.

21. Parizi ACG, Barbosa RL, Parizi JLS, et al. A comparison between the concentration of mast cells in squamous cell carcinomas of the skin and oral cavity. An Bras Dermatol. 2010;85:811-818.

22. Mehrotra R, Gupta DK. Exciting new advances in oral diagnosis: avenues to early detection. Head Neck Oncol. 2011;3:33.

23. Amagasa T, Yamashiro M, Uzawa N. Oral premalignant lesions: from a clinical perspective. Int J Clin Oncol. 2011;16:5-14.

24. Cuevas Gonzalez JC, GaitanCepeda LA, Borges Yanez AS, et al. p53 and p16 in oral epithelial dysplasia and oral squamous cell carcinoma: a study of 208 cases. Indian J Pathol Microbiol. 2016;59:153-158.

25. Guo X, Zhai L, Xue R, et al. Mast cell tryptase contributes to pancreatic câncer growth through promoting angiogenesis via activation of angiopoietin-1. Int $J$ Mol Sci. 2016;17:1-11.

26. Micu GV, Stăniceanu F, Sticlaru LC, et al. Correlations between the density of tryptase positive mast cell (DMCT) and that of new blood vessels (CD105+) in patients with gastric cancer. Rom J Intern Med. 2016;54:113-120.

27. Dyduch G, Kaczmarczyk K, Okoń K. Mast cells and cancer: enemies or allies? Pol J Pathol. 2012;63:1-7.

28. Rodini CO, Batista AC, Lara VS. Comparative immunohistochemical study of the presence of mast cells in apical granulomas and periapical cysts: possible role of mast cells in the course of human periapical lesions. Oral Surg Oral Med Oral Pathol Oral Radiol Endod. 2004;97:59-63.

29. Kathuriya PT, Bartake AR, Palaskar SJ, et al. CD34 and mast cell analysis in normal oral mucosa and different grades of oral squamous cell carcinoma: a comparative study. J Clin Diagn Res. 2015;9:ZC61-ZC64. 
30. Zaidi M, Mallick A. A study on assessment of mast cells in oral squamous cell carcinoma. Ann Med Health Sci Res. 2014;4:457-460.

31. Kinra M, Ramalingam K, Sarkar A, et al. Comparison of mast cell count and mast cell density in normal mucosa, oral leukoplakia, oral lichen planus, oral submucous fibrosis and oral squamous cell carcinoma-a study on 50 cases. J Pharm Sci Innovation. 2012;1: 4-11.

32. Birajdar SS, Radhika M, Paremala K, et al. Expression of Ki-67 in normal oral epithelium, leukoplakic oral epithelium and oral squamous cell carcinoma. J Oral Maxillofac Pathol. 2014;18: 169-176.

33. Sathyakumar M, Sriram G, Saraswathi T. Immunohistochemical evaluation of mast cells and vascular endotelial proliferation in oral precancerous lesion-leukoplakia. J Oral Maxilofac Pathol. 2012;16: 343-348.

34. Michailidou EZ, Markopoulos AK, Antoniades DZ. Mast cells and angiogenesis in oral malignant and premalignant lesions. Open Dent J. 2008;2:126-132.

35. Jandinski JJ, Sonis S, Doku HC. The incidence of mast cells in selected oral lesions. Oral Surg. 1972;34:245-248.

36. Oliveira-Neto HH, Leite AF, Costa NL, et al. Decrease in mast cells in oral squamous cell carcinoma: possible failure in the migration of these cells. Oral Oncol. 2007;43:484-490.

37. Jahanshahi G, Sabaghian M. Comparative immunohistochemical analysis of angiogenesis and mast cell density in oral normal mucosa and squamous cell carcinoma. Dent Res J (Isfahan). 2012;9:8-12. 